\title{
Analysis of the Restructured Energy Market in the Framework of Game Theory: Iran's Power Industry
}

\author{
Shahram Moeeni \\ Ph.D. Candidate, Department of Economics, University of Isfahan (Iran) \\ Email: shahram.moeeni@gmail.com
}

Alimorad Sharifi

Department of Economics, University of Isfahan (Iran)

Email: alimorad@ase.ui.ac.ir

Rahman Khoshakhlagh

Department of Economics, University of Isfahan (Iran)

Email: rahmankh44@yahoo.com

\section{Karim Azarbayjani}

Department of Economics, University of Isfahan (Iran)

Email: k_azarbayjani@ase.ui.ac.ir

DOI: 10.6007/IJAREMS/v2-i5/301 URL: http://dx.doi.org/10.6007/IJAREMS/v2-i5/301

\begin{abstract}
Restructuring of electricity market in Iran has been accepted and operationalized following the power market in industrial countries. Increasing of efficiency through insertion of economic considerations and transition from monopoly to more competitive conditions in order to become closer to the optimal status are the basis to accept restructuring. Given to the market structure, imperfect competition is ultimately fulfilled in this market that games theory solutions should be used to analyze it. On the other side, given to bidding and pay-as-bid (PAB) in Iran's electricity market, supply function equilibrium (SFE) models is suitable for analysis. Therefore, having proposed function and the suitable theoretical model and estimated marginal cost function and uncertainty demand parameters, in the framework of SFE approach, the optimal supply function equilibrium of one of the firms of the electricity market in Isfahan was extracted by means of MATLAB software. Then it was compared with the proposed supply function. The obtained results revealed that the current proposed supply function does not conform to the theoretical optimal supply function in Nash equilibrium.
\end{abstract}

Key words: Restructuring, Games theory, SFE approach, Pay-as-bid, Iran's electricity market 
JEL classification: C70 ‘D21 ‘D40،L13،Q41

\section{Introduction}

In much of the twentieth century electricity users across the world had to buy electric energy from the Utility which held the monopoly to supply electricity. These utilities had mostly a vertically integrated structure and were responsible to produce electric energy, transfer it to load centers from power plants and distribute the energy among applicants simultaneously. However, some economists in the 1980's proposed this pattern will no longer be used. They believed that the monopolized status of the utilities gave rise to unnecessary investments, decreased motivation for effective exploitation and generally uneconomic and suboptimal performance in generation and distribution of the electric energy. Mistakes and inefficiency of these companies are simply imposed on people and energy consumers. Dependency of most of these companies on the governments and order prices are the origin of some problems and inefficiencies. For example, some national and public utilities have an enormous income due to their monopolistic status. This is while some other companies can not adjust their rate to the extent to cover expenses and achieve the essential capability for new fundamental investments.

Economists suggest that electricity should be supplied as a product according to market rules instead of being supplied with monopolistic regulations or based on governmental policies and it would be led to Pareto optimality and enhancement of general profit. This approach was an origin of a general deregulation in western economies in the 1970's which had changed air lines, transportation and so on before electricity industry. It was conceived in all these sectors that a monopolistic market or a market with regulations is the most effective way for offering of goods or services to customers. Evidently, specific characteristics of such products made them unsuitable for trading in free markets. But adherents of deregulation asserted specific characteristics of such products are not impassable obstacles for a free and competitive supply (Kreshen \& Straback 2004).

In recent decades industries such as electricity, gas and communications have been subjected to structural changes towards deregulation and privatization across the world. It is expected that the intended restructuring for these industries encourages competition in generation and supply and is finally resulted in saving, reduction of expenses and price of products and services and efficiency. This is while the generation and consumption process of electric energy could be divided into three steps of generation, transfer and distribution. Generation and distribution of electric energy could move towards more competitiveness potentially and the technology allows more than one firm exists in the market while transfer has the nature of natural monopoly. In addition to theoretical principles, experience of pioneer countries in restructuring of electricity market shows helpfulness of competition in generation and distribution.

Anyway, basic changes have been created in power structures and systems in industrial countries regarding market building activities in recent decades by developing economic knowledge in the field of market performance and comprehensiveness of the paradigm on the basis of market mechanism to improve and strengthen economic performance in all sectors. These basic changes that are occurred by a process called restructuring means extensive changes in rules and structures of the market and moving towards modern market-oriented 
structures. Objective of restructuring in the utility industry is to create higher productivity, reach low level of prices and offer better services to consumers through ways such as reinforcement of competition. Although three purposes of economic efficiency, equity and customer freedom of choice are usually regarded as reasons for moving towards restructuring in electricity markets by policy makers (Shweppe, 1988), it is clear that the ultimate goal is to achieve market mechanism, competitiveness and thus Pareto efficiency economically.

If electricity is indeed regarded as a product, kilowatt-hour should be usable like any other product at the moment the consumer decides to use it as consumer goods or production input. But despite recent progresses in microgeneration technology, this has not been realized and practiced commercially and secure and continuous supplying of high amounts of electric energy requires large power plants and their connection to the consumer through transfer and distribution channels. This energy should be produced to the degree that is consumed at that moment.

Therefore, the first difference between electric energy and other products is that electric energy exchange is applied to a certain amount of kilowatt-hour that should be produced, delivered and consumed simultaneously during a specific time period. In other words, electric energy has inseparably been associated with a physical system (electricity network) that its behavior is faster than any market. Supply and demand or generation and loading in physical system of power must be in balance at any second. If such balance is not established, the system would be collapsed where not only a transaction is rejected but it would be led to extensive outage of electric energy along with severely harmful economic and social consequences. No economy could agree with mechanisms of a market which imposes the possibility of occurring such events due to even short-term imbalances. Moreover, restoring of the power system following these collapses is a complex, expensive and time-consuming process. Hence, balance of supply and demand of electric energy in short-term is a process which could not be controlled by a relatively slow and unreliable entity like market. Creating balance in short-term with any possible cost is essential through a strategy that does not rely on the market for selection and dispatch.

Currently, the electricity industry across the world is moving towards more competitive markets and restructuring process. It is passing from a monopolistic structure towards more competitive markets and a new structure in Iran too. By taking a look at the past it could be observed that primary units of electricity energy generation were established in Iran by the private sector but gradually role of the government was reinforced so that since the 1970's the government controlled it completely.

However, Iran's electricity market has had some movements towards restructuring on the basis of market system during recent nine years according to the government's regulations. In this new structure manufacturers compete with each other in certain frameworks in order to sell energy. Market regulatory authority, market manager and National Center for Governance and National Power Grid Monitoring (dispatching) are entities which organize performance of the electricity energy market in Iran in order to achieve reliability as well as optimization.

Tender in Iran's electricity energy market is single-ended and wholesale market based on power pool model is the market model. Manufacturers in the electricity energy market offer their proposed function to market manager (who exploits this system). On the other hand, there is demand along with uncertainty. When amount of total productive energy and 
productive energy of each firm is determined, it is paid to manufacturers based on their proposed price in the framework of supply function and not the unique balanced price. Payment in unique pay auction that is used in some electricity energy markets in other countries is monotonous and based on the above balanced price.

\section{Theoretical principles and background}

Given to the above differences and some other characteristics, market formation and competition in the electricity industry has been led to considerable changes in its performance and naturally new problems have also been proposed. The issue of pricing is one of the most important changes that its structure has changed basically. Thus, auction approach becomes especially important.

Restructured electricity markets in the world including Iran act in the context of market structure based on limited firms for two purposes of providing reliability from one side and ensuring maintenance of optimum strategic selection of firms (agents) under uncertainty conditions of demand from the other side. They usually ask the electricity firms to represent their selected strategy to supply electricity in supply function framework, i.e. a set of bid prices to the market manager. To put it differently, each firm announces its possible supply values with the bid price for any amount in the form of a function entitled proposed supply function to market manager. Then the market manager chooses supply level of each firm based on the minimum bid price which provides consumers' advantage. The auction approach would be pay as bid or unique pay.

Restructuring and the created competition is in a way that decisions of each firm would affect decision-making of its competitors. Hence, strategy of each firm should be selected based on the game theory and considering demand uncertainty on the basis of the expected profit maximization given to the selected supply function system and pay as bid and limited manufacturers in electricity markets including Iran's electricity market.

Supply function solution is more appropriate than those of Bertrand and Kourno especially in terms of reliability of the system under uncertainty conditions (Klemprer \& Mir, 1989). Anyway, representing supply function is the strategic space for suppliers in Iran's electricity market. A level of competition is created among firms in this framework that naturally helps firms and stronger orientation of production for optimal efficiency and allocation in the whole economy.

Therefore, as electricity market of each player should offer both its supply level and corresponding price and each player should optimize its supply level and price simultaneously in the games model based on supply function equilibrium, framework of supply function equilibrium model is proportional with the electricity energy market and thus this basic model is used here to calculate Nash equilibrium.

Given to this structure in the present survey, it is tried to choose the most appropriate model by considering previous theoretical studies and the existing models especially Holmberg's (2009) study from one side and characteristics of Iran's electricity energy market from the other side. Then optimal supply function of the model under study (Montazeri Power Plant in Isfahan province) is exploited. As it will be shown in the following, the problem to optimize electricity generating company will be written as an optimization problem of the expected profit. Demand, too, is considered with uncertainty. The process of solution is 
ultimately led to differential equations which give supply function strategy of the firm and combination of balanced supply function strategies as Nash equilibrium by considering appropriate boundary conditions. Exploiting the explicit form of supply function requires to recognize final cost structure from one side and demand uncertainty from the other side. Therefore, essential estimations about the selected firm from electricity energy market in Iran are obtained. Finally, compatibility or incompatibility of optimal supply function with the realized and proposed supply functions in the electricity energy market would be analyzed.

Extensive studies have been accomplished about the structure of electrical energy market especially in recent years. Garcia and Arbelaez (2002) conducted simulations for the electricity market in Colombia in a study entitled "market power analysis for the electricity market in Colombia". They applied dynamic Corno's model to show probable impacts of merger in the wholesale electricity market in this country. The above simulations indicate level of prices in post-merger is averagely $24 \%$ more than the pre-merger. Also it is shown that prices are reduced in some cases by adding a high number of predicted contracts to the model.

Anderson and Philpot (2002) studied the problem with which energy manufacturer is encountered through supplying its generation in a wholesale electricity market in a paper entitled "applying supply function for production proposal in the electricity market". Settlement price of the market is determined using sealed bids. Market demand and behavior of players are considered with uncertainty and modeling is based on explaining the problem of manufacturers' optimization. In this paper a new approach is used to propose uncertainty and thus a considerable part of it is related to market distribution function. Market distribution function $\psi(\mathrm{q}, \mathrm{p})$ illustrates a probability that point $(\mathrm{q}, \mathrm{p})$ is placed in the price space and higher than the residual demand. It is assumed that $\psi(\mathrm{q}, \mathrm{p})$ is continuous and its uniqueness is proved. In the second part of the paper, necessary conditions to optimize the expected profit $\mathrm{V}(\mathrm{s})=\int_{\mathrm{s}} \mathrm{R}(\mathrm{q}, \mathrm{p}) \mathrm{d} \psi(\mathrm{q}, \mathrm{p})$ are developed. The manufacturer's problem is to find curve s, i.e. a supply function which maximizes his expected profit $V(s)$ in lieu of the given market distribution.

Anderson and Zhou (2002) analyzed optimal supply of an energy supplier in a wholesale market of electricity energy in the framework of pool model in a study entitled "necessary and sufficient conditions of bids in the electrical energy market". Market demand is regarded with uncertainty and supply curve is undescending and continuous. A ceiling price is assumed. Each firm exploits demand distribution function of the market for its supply by recognizing probability distribution of demand and previous observations of competitors' supply behavior. Finally, the necessary condition to exploit optimal supply function and that of local optimization are obtained according to this basis and in the framework of optimization of the expected profit.

Federico and Rahman (2003) conducted a study entitled "biding in the electricity market with pay as bid" and stated their major motivation to write this article was to modify transaction rules in England and Wales. Pricing in this market was changed from unique pay option to pay as bid auction. Hence, unique pay option (UPA) and pay as bid auction (PABA) were studied under total competition and monopolistic conditions. Finally, authors concluded 
that using PABA was led to increased consumer's surplus and decreased generation level both in total competition and monopolistic conditions.

Niu (2005) studied the structured electricity markets in a paper entitled "strategies of supply function equilibrium with fixed forward contracts". In the beginning of the paper he recalled that the regulated framework of electrical energy market was replaced with competition in many countries during previous fifteen years. Electricity firms compete with each other in such environment through giving suggestions in the instantaneous electricity market and mutual contracts. Supply function equilibrium model was suggested and analyzed under asymmetrical conditions for restructured electricity markets, while supply functions were considered linear. Limitations to transfer and existence of forward contracts were added to the model as well. Finally, the recommended model was executed for ERCOT electricity market and impact of contracts on this market was evaluated.

Oren and Sioshansi (2006) represented an experimental analysis of supply function equilibrium model in the instantaneous electricity market in Texas in an article entitled "studying the efficiency of supply function equilibrium model: experimental analysis of ERCOT ${ }^{1}$ electricity market". First a market with ex-ante mutual sales contracts was considered and then the essential conditions to offer optimal recommendations by manufacturers were obtained. Finally, a set of ex-ante optimal supply functions were exploited by estimating the expenses and theoretical optimal supply functions were compared with real suggestions using a nonparametric behavioral model.

Holmberg (2006) considered an electricity market under conditions of uniform price auction and demand uncertainty in an article entitled "uniform supply function equilibrium with capacity limitations". Manufacturers in this market offer their bids in the form of supply function. In the balanced state, each firm represents a supply function which maximizes its expected profit by considering supply functions of its competitors. He showed various equilibriums are possible in this market and unity and symmetry of supply function equilibrium could be concluded through considering some assumptions.

\section{The model of supply function equilibrium under demand uncertainty}

The selected model in the present survey is explained briefly in this section. Problem of firms' optimization under uncertainty conditions in the framework of a basic model according to Holmberg's (2009) model is considered as below in order to perceive the optimal behavior in the framework of games theory and uncertainty conditions. Demand value of the market is shown with $\varepsilon$ that its amount is not definite and certain but probability of occurrence of any amount of it is shown with a probability density function. The proposed total supply of all firms is equal to $\varepsilon^{*}$. Supply function equilibrium is shown with $S_{i}(p)$ for the manufacturer $i$ and $p$ shows price. Opposite of this supply function is shown with $p_{i}\left(\mathbf{S}_{i}\right)$. Also $S_{-i}(p)$ and $S(p)$ are used to indicate supply function of the competitor and total supply function in the market respectively. Each firm maximizes the expected profit that is shown with $E\left(\pi_{i}\right)$ by offering optimal supply function. If market demand is $\varepsilon \leq \varepsilon^{*}$, the accepted product of the firm with this demand value would be $\varepsilon-S_{-i}(p(\varepsilon))$. The proposed profit accepted by a differential unit of

${ }^{1}$ Electricity Reliability Council of Texas 
supply is $\mathbb{}\left(p \rrbracket_{\mathbf{i}}\left(S_{i}\right)-\mathbf{C}^{I}\left(S_{i}\right)\right) d S_{i}$. Therefore, the firm's profit for the realized demand $\varepsilon$ in the market is calculated using sum of profit of each unit until reaching the accepted product level by the firm i. Given to very small manufacturing units, the above addition is converted into the below integral:

$\pi_{i}(\varepsilon)=\int_{0}^{\varepsilon-S_{-i}(P(\varepsilon))}\left[P_{i}\left(S_{i}\right)-C^{\prime}\left(S_{i}\right)\right] d S_{i} \quad$ if $\varepsilon \leq \varepsilon^{*}$

The firm intends to maximize its expected profit. The expected profit of firm $\mathrm{i}$ is calculated through integrating demand given to the probability of realization of any amount of demand. Thus it is concluded that:

$E\left(\pi_{i}\right)=\int_{0}^{s^{*}} f(\varepsilon) \int_{0}^{s-s_{i}(p(s))}\left[p_{i}\left(s_{i}\right)-C^{\prime}\left(s_{i}\right)\right] d s_{i} d \varepsilon$

Capacity and supply function of all firms is similar when they are symmetrical. The amount of accepted demand of any firm is related to ratio of the firm's capacity to total capacity that is shown with $1 / \mathrm{N}$ if firms are asymmetrical and supply function of each firm is proportional to its capacity. Now if demand is more than market supply, we would have:

$E\left(\pi_{i}\right)=\int_{0}^{\varepsilon^{*}} f(\varepsilon) \int_{0}^{s-s_{i}(p(s))}\left[p_{i}\left(s_{i}\right)-C^{y}\left(s_{i}\right)\right] d s_{i} d \varepsilon+\int_{s^{*}}^{\hat{\varepsilon}} f(\varepsilon) \int_{0}^{\varepsilon^{*} / N}\left[p_{i}\left(s_{i}\right)-C^{y}\left(s_{i}\right)\right] d s_{i} d \varepsilon$

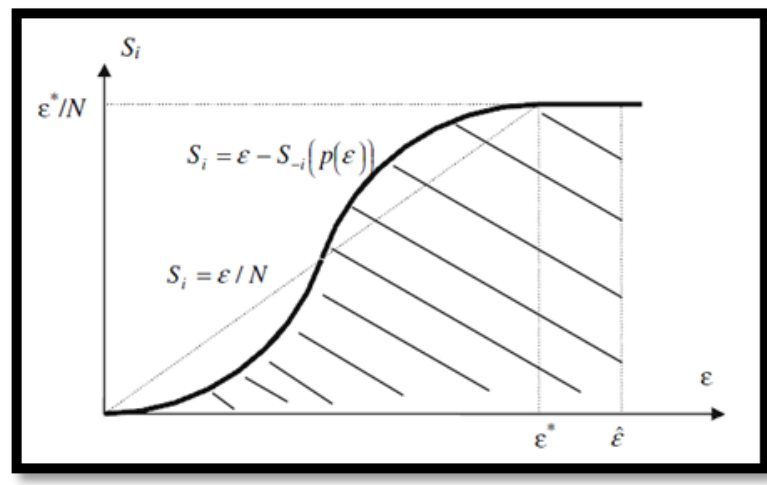

Figure 1- integration range to calculate the expected profit

The second term of the above formula shows that demand is more than the proposed total supply of firms and the accepted supply amount of the firm is equal to $\varepsilon^{*} / \mathrm{N}$. Now if integral order of the above term is changed, it is converted into the following form. Figure (1) has been displayed to clarify integration range.

$$
\begin{aligned}
E\left\{\pi_{i}\left[p_{i}\left(s_{i}\right)\right]\right\} & =\int_{0}^{\frac{\varepsilon^{*}}{N}}\left[p_{i}\left(s_{i}\right)-\mathrm{C}^{\prime}\left(s_{i}\right)\right] \int_{s_{i}+s_{-i}\left[p_{i}\left(s_{i}\right)\right]}^{\varepsilon^{*}} f(\varepsilon) d \varepsilon \mathrm{d} s_{i} \\
& +\int_{0}^{\frac{\varepsilon^{*}}{N}}\left[p_{i}\left(s_{i}\right)-\mathrm{C}^{x}\left(s_{i}\right)\right] \int_{\varepsilon^{*}}^{\varepsilon} f(\varepsilon) d \varepsilon \mathrm{d} s_{i}
\end{aligned}
$$




$$
\begin{array}{r}
=\int_{0}^{\frac{\varepsilon^{*}}{N}}\left[p_{i}\left(s_{i}\right)-\mathrm{C}^{\prime}\left(s_{i}\right)\right] \int_{s_{i}+s_{-i}\left[p_{i}\left(s_{i}\right)\right]}^{\hat{\varepsilon}} f(\varepsilon) d \varepsilon \mathrm{d} s_{i} \\
E\left\{\pi_{i}\left[p_{i}\left(s_{i}\right)\right]\right\}=\int_{0}^{\frac{\varepsilon^{*}}{N}}\left[p_{i}\left(s_{i}\right)-\mathrm{C}^{\prime}\left(s_{i}\right)\right]\left[1-\mathrm{F}\left(s_{i}+s_{-i}\left[p_{i}\left(s_{i}\right)\right]\right)\right] \mathrm{d} s_{i}
\end{array}
$$

The above result could be interpreted in a way that the firm's expected profit is obtained through sum of the expected profit of manufacturing units. The expected profit of each firm that is shown with $\varphi_{i}\left[s_{i}, p_{\mathrm{i}}\left(s_{i}\right)\right]$ is obtained through $\left[p_{i}\left(s_{i}\right)-C^{\prime}\left(s_{i}\right)\right]$ multiplied by probability of offer acceptation by this unit. It is indeed the probability that demand is higher than $s_{i}+s_{-i}\left[p_{i}\left(s_{i}\right)\right]$. Given that the firm intends to propose supply function which maximizes the expected profit, first-order condition of profit maximization is obtained as below:

$$
\begin{aligned}
& \frac{\partial \varphi_{i}}{\partial p_{\mathrm{i}}}=1-\mathrm{F}\left[\mathrm{s}_{-\mathrm{i}}\left(p_{\mathrm{i}}\left(s_{i}\right)\right)+s_{i}\right] \\
& -s_{-i}^{\prime}\left(p_{i}\left(s_{i}\right)\right)\left(p_{i}\left(s_{i}\right)-C^{\prime}\left(s_{i}\right)\right) f\left[s_{-i}\left(p_{i}\left(s_{i}\right)\right)+s_{i}\right]=0 \quad \forall s_{\mathrm{i}} \\
& \quad \in\left[0, \varepsilon^{*} / N\right]
\end{aligned}
$$

Relation (5) could be written as below, as only equilibriums with ascending and unique supply functions are considered:

$$
\begin{gathered}
1-F\left[S_{-i}(p)+S_{i}(p)\right]-S_{-i}^{t}(p)\left(p-C^{\prime}\left(S_{i}(p)\right)\right) f\left[S_{-i}(p)+S_{i}(p)\right]=0, \\
\forall p: S_{i}(p) \in\left(0,{ }^{*} / N\right)
\end{gathered}
$$

Since supply function is considered proportional to the capacity, then we have $S_{-i}(p) \equiv(N-1) S_{i}(p)$

Thus, relation (6) is converted into the below form:

$$
\begin{gathered}
1-F\left[N S_{i}(p)\right]-(N-1) S_{i}^{\prime}(p)\left(p-C^{\prime}\left(S_{i}(p)\right)\right) f\left[N S_{i}(p)\right] \\
=0 \\
\forall p: S_{i}(p) \in\left(0, \varepsilon^{*} / N\right)
\end{gathered}
$$


To simplify solution, differential equation (7) is written as an equation in terms of $p(\varepsilon)$. Therefore, relation (7) is obtained as below given to the equilibrium in $\varepsilon=N S_{i}(p(\varepsilon))$ $\mathbf{S}_{i}^{I}=\frac{1}{N p^{I}(\varepsilon)}$ :

$1-F(\varepsilon)-\frac{N-1}{N p^{\prime}(\varepsilon)}\left(p(\varepsilon)-C^{\prime}(\varepsilon / N)\right) f(\varepsilon)=0 \quad \forall \varepsilon \in\left[0, \varepsilon^{*}\right]$

Finally, this differential equation is converted into an impartial differential equation with some changes that becomes complete using the integration factor. Then general response of this differential equation could be obtained that contains an unknown constant of integration $A$ and as a result it shows various supply function equilibriums. A boundary condition is needed to obtain and attribute a certain ratio to this constant. This boundary condition is exploited based on the fact that the highest suggested amount, i.e. suggestion of total capacity would be represented in maximum price (suggestion). Therefore, constant of integration is determined exactly by the final condition $p(\varepsilon)=p$ (see Holmberg, 2009). At last the following relation is obtained as the unique solution:

$p(\varepsilon)=\frac{N[1-F(\bar{\varepsilon})]^{\frac{N-1}{N}} \bar{p}+\int_{\varepsilon}^{\bar{\varepsilon}}(N-1) C^{\prime}(u / N) f(u)[1-F(u)]^{\frac{N-1}{N}-1} d u}{N[1-F(\varepsilon)]^{\frac{N-1}{N}}}$

$\forall \varepsilon \in[0, \bar{\varepsilon}]$

The above relation is converted into the below one by assuming that demand has generalized pareto distribution and $f$ and $F$ have been replaced with probability density and generalized pareto distribution function.

$p(\varepsilon)=\frac{N(\alpha \bar{\varepsilon}+\beta)^{\frac{1-N}{\alpha N}} \bar{p}+\int_{\varepsilon}^{\bar{\varepsilon}}(N-1) C^{\prime}(u / N)(\alpha u+\beta)^{\frac{1-N}{\alpha N}-1} d u}{N(\alpha \varepsilon+\beta)^{\frac{1-N}{\alpha N}}}$

$\alpha$ and $\beta$ are parameters of generalized pareto distribution and other variables have been explained before.

\section{Estimation and results}

It is notable that relation (10) is not exactly the optimal supply function or its opposite for the firm under the above-mentioned assumptions, because it gives price in terms of total demand. The relation between total demand and supply of a special firm has previously been obtained under equilibrium condition and model assumptions, thus opposite of supply function of the firm under study is rewritten as below.

$p_{\mathbf{1}}\left(\mathbf{s}_{\mathbf{1}}\right)=\frac{N(\alpha \bar{\varepsilon}+\beta)^{\frac{1-N}{\alpha N}} \bar{p}+\int_{\mathrm{Ns}_{\mathbf{1}}}^{\bar{\varepsilon}}(N-1) C^{I}(u / N)(\alpha u+\beta)^{\frac{1-N}{\alpha N}-1} d u}{N\left(\alpha \mathbf{s}_{1}+\beta\right)^{\frac{1-N}{\alpha N}}}$ 
The last relation is used to estimate optimal supply function of the firm. South Isfahan Power Plant was considered in this survey for the experimental study which has practical capacity equal to $733 \mathrm{MW}$.

Some information about this firm and other firms in Isfahan and Chahar Mahal Bakhtiari regions are represented in Tables (2) and (3).

In order to estimate the optimal supply function in this section marginal cost function should be extracted. To this end, variable cost function should first be extracted and then derivation is conducted to obtain marginal cost function. On the other hand, we know that cost of fuel is the most major variable cost for power plants and there is a direct relation between degree of fuel consumption or indeed the input energy per hour and production value of the units per hour. This is referred to as input-output relation of the power plant. A second class relation is considered as below to estimate the input-output feature of the power plant based on technical concepts.

$H=a_{0} q^{2}+a_{1} q+a_{2}$

Where $H$ shows the input energy per hour (based on Mega Calorie) and $q$ is the production value of the power plant per hour (based on Megawatt Hour). In order to estimate this relation the statistics related to fuel consumption of the power plant based on cubic meter and degree of production based on Megawatt were used.

Table 1- Power plants of Isfahan and Chahar Mahal Bakhtiari provinces

\begin{tabular}{|c|c|c|c|c|}
\hline Row & $\begin{array}{c}\text { Name of the power } \\
\text { plant }\end{array}$ & $\begin{array}{c}\text { Nominal capacity } \\
\text { MW }\end{array}$ & $\begin{array}{c}\text { Practical capacity } \\
\text { MW }\end{array}$ & $\begin{array}{l}\text { Percent of total } \\
\text { nominal capacity }\end{array}$ \\
\hline 1 & Isfahan & 835 & 830 & 14.22 \\
\hline 2 & $\begin{array}{l}\text { Shahid Mohammad } \\
\text { Montazeri }\end{array}$ & 1600 & 1540 & 27.25 \\
\hline 3 & Hesa & 58 & 42 & 0.99 \\
\hline 4 & Natanz Power Plant & 48 & 34 & 0.82 \\
\hline 5 & Zayanderud Dam & 55.5 & 55.5 & 0.95 \\
\hline 6 & Koohrang Dam & 39.3 & 39.3 & 0.67 \\
\hline 7 & $\begin{array}{l}\text { Mobarakeh Steel } \\
\text { Company }\end{array}$ & 309 & 225 & 5.26 \\
\hline 8 & Esfahan Steel Company & 165 & 136 & 2.81 \\
\hline 9 & $\begin{array}{l}\text { South Isfahan Power } \\
\text { Plant }\end{array}$ & 954 & 733 & 16.24 \\
\hline 10 & Kashan & 324 & 255 & 5.52 \\
\hline 11 & Zavareh & 484 & 324 & 8.24 \\
\hline 12 & Karun-4 Dam & 1000 & 1000 & 17.03 \\
\hline
\end{tabular}

Source: Comparative statistics of electricity industry, 2012 and Isfahan grid management company 
Table 2- South Isfahan Power Plant

\begin{tabular}{|l|c|c|c|c|c|c|}
\hline $\begin{array}{c}\text { Name of } \\
\text { the } \\
\text { power } \\
\text { plant }\end{array}$ & $\begin{array}{c}\text { Unit } \\
\text { type }\end{array}$ & $\begin{array}{c}\text { Consume } \\
\text { r gas }\end{array}$ & $\begin{array}{c}\text { Practical } \\
\text { capacity } \\
\text { MW }\end{array}$ & $\begin{array}{c}\text { Total production } \\
\text { in terms of } \\
\text { million }\end{array}$ & $\begin{array}{c}\text { Share } \\
\text { from } \\
\text { capacit } \\
\text { y }\end{array}$ & $\begin{array}{c}\text { Share from total } \\
\text { production }\end{array}$ \\
\hline South & Gas & 835301 & 733 & 4069.1 & 16.2 & 15.5 \\
\hline
\end{tabular}

Source: Comparative statistics of electricity industry, 2012 and Isfahan grid management company

Table 3- Results of estimating the input-output curve of South Isfahan Power Plant

\begin{tabular}{|c|c|c|c|c|c|}
\hline \multicolumn{2}{|c|}{$a_{0}$} & \multicolumn{2}{c|}{$a_{15}$} & \multicolumn{2}{c|}{$a_{2-}$} \\
\hline Coefficient & t-statistic & Coefficient & t-statistic & Coefficient & t-statistic \\
\hline 0.938 & 1.96 & 18.68 & 11.78 & 201056 & 2.36 \\
\hline
\end{tabular}

Source: Accurate calculations

The power plant used gas as fuel for conditions under study and the consumer gas was converted into input energy using fuel heating value. Thus, gas heating value equal to 8.763 $\mathrm{Mcl} / m^{\text {a }}$ was used. The power plant acts at standard temperature. The results are summarized in Table 4 that are consistent with some previous studies (Dehesh 2010, Nazemi 2012).

Therefore, for the South Power Plant we can write:

$$
H\left(\frac{M c l}{h}\right)=0.938 q^{2}+1868 q+201056
$$

Fuel price equal to $700^{R l s} / m^{\text {a }}$ was used to obtain the relation related to total variable cost (Isfahan Management Company of Electricity Network, 2012). Given that heating value of each cubic meter gas is equal to $8.763^{\mathrm{Mcl}} / \mathrm{m}^{\text {a }}$ (Dehesh, 2010) the input-output relation for South Power Plant for instance will be converted into cost relation.

$$
\text { TVC }\left(\frac{\text { Rial }}{h}\right)=\frac{700}{8.763\left(0.938 q^{2}+1868 q+201056\right)}
$$

Then the relation related to marginal cost of the power plant is obtained as below:

$$
M C=\frac{700}{8.763(2 \times 0.938 q+1868)}
$$

According to Holmberg's model (2009), electricity demand that has Pareto generalized distribution is considered. The generalized Pareto cumulative distribution function and its probability density function are defined as below.

$$
\begin{aligned}
& F(x)=1-\sigma \bar{k}(k x+\sigma)_{{ }^{\frac{1}{k}}}^{\frac{-1}{k}} \\
& f(x)=\sigma^{\frac{1}{k}}(k x+\sigma)^{\frac{1}{k}-1}
\end{aligned}
$$

Considering electricity demand and consumption statistics of the country in this survey at peak times in July and August 2013 and using Generalized Method of Moments, parameters $k$ 
and $\sigma$ in this distribution were estimated. Values of $k$ and $\sigma$ were extracted from the below relations.

$\hat{k}_{\text {MOM }}=\left(1-\bar{x}^{2} / s^{2}\right) / 2$
$\hat{\sigma}_{\text {MOM }}=\frac{\bar{x}\left(\bar{x} / s^{2}+1\right)}{2}$

where $\bar{x}$ and $s^{\mathbf{z}}$ indicate mean and variance of the sample respectively. Estimated values of the parameters are reported in Table (5).

Table 4- Results of the estimated parameters in July and August 2012

\begin{tabular}{|l|c|c|c|c|}
\hline \multicolumn{1}{|c|}{ Parameter } & $\hat{k}_{\text {MOM }}$ & $\widehat{\sigma}_{\text {MOM }}$ & $\bar{x}$ & $s^{\bar{D}}$ \\
\hline Estimation & -508.41 & 17165505 & 33696.86 & 105621 \\
\hline
\end{tabular}

Source: Accurate calculations

Table 5- Power and maximum price in Iran's electricity industry

\begin{tabular}{|c|c|c|c|}
\hline $\begin{array}{c}\text { The appointed } \\
\text { nominal power } \\
(\mathrm{MW})\end{array}$ & $\begin{array}{c}\text { Practical power } \\
(\mathrm{MW})\end{array}$ & $\begin{array}{c}\text { The produced } \\
\text { power at peak } \\
\text { times (MW) }\end{array}$ & $\begin{array}{c}\text { Maximum approved } \\
\text { price in the market } \\
\text { Rial - Megawatt }\end{array}$ \\
\hline 65212 & 57522 & 42245 & 330000 \\
\hline
\end{tabular}

Source: Isfahan Electric Network Management Company and Comparative statistics of electricity industry, 2012

Maximum possible price in the market, $\bar{p}$, according to Isfahan Electric Network Management Company in 2012, the appointed nominal power, practical power and the produced power at peak times are also represented in Table 6. Finally the explained model in relation (11) is executable rapidly using MATLAB software by extraction of the marginal cost function and other necessary data in this relation including the firm information, market demand information, capacity of competitors and price ceiling. Structure of the electricity market is in a way that a separate market is held for each 24 hours. It means that manufacturers offer 24 demand functions (proportional with any time of the day) to the market daily for each manufacturing unit. List of the proposed price-value of one unit of the power plant under study in the market is available in different days and hours. Prices corresponding to different production values due to model implementation were calculated for peak hours of consumption on July 22, 2012 and the price-optimal value list based on supply function equilibrium approach (SFE) was extracted. It is reported for the power plant in Table 7. Finally, the propped supply function of the firm in the market was compared with the extracted optimal supply function based on the model diagrammatically. It is noteworthy that the proposed price-value for South Isfahan Power Plant is conducted by Isfahan Regional Electric Company which undertakes fuel supply too. 
Table 6- Set of the extracted optimal price-value for the power plant unit (159 MW)

\begin{tabular}{|l|c|c|c|c|c|}
\hline Power & 75 & 83 & 91 & 100 & 108 \\
\hline Price & 328922 & 329005 & 329101 & 329210 & 329307 \\
\hline Power & 116 & 125 & 133 & 141 & 150 \\
\hline Price & 329423 & 329591 & 329724 & 329841 & 329999 \\
\hline
\end{tabular}

Source: Accurate calculations (values are based on Megawatt and prices are based on Rial)

Figure 2- The proposed and optimal price-value diagram extracted from the model for $159 \mathrm{MW}$ unit

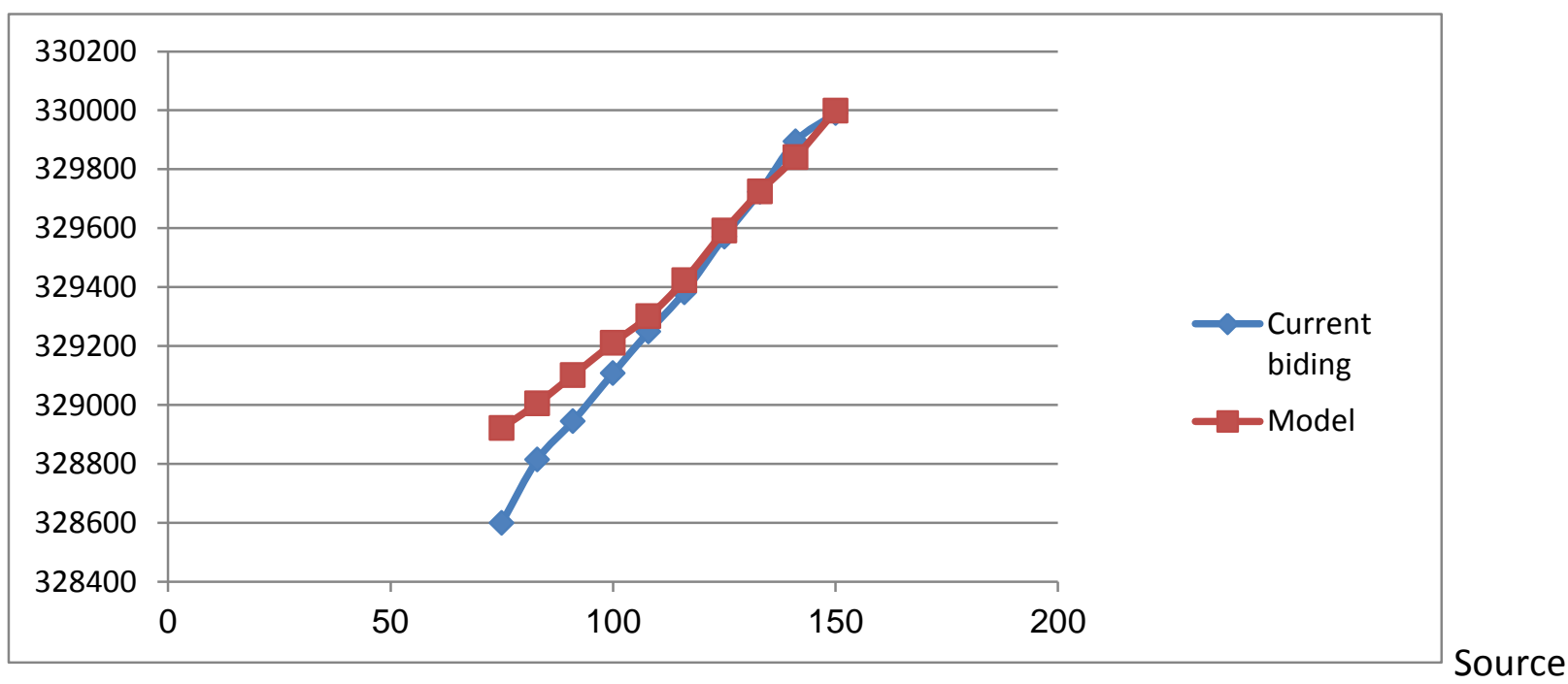

: Accurate calculations (values are based on Megawatt and prices are based on Rial)

As it can be observed although the proposed prices of the power plant are relatively conformed with calculated prices arising from the model for values close to the capacity in the South Power Plant but the proposed and calculated prices arising from the model for production quantities less than the capacity are different and the recent prices are higher. Indeed with regard to profit maximization in the electricity market and despite the price ceiling and considering the cost in order to present supply function in equilibrium state with values less than the capacity it will be possible to suggest optimal price-value set that guarantees maximization of the expected profit. This shows that firms are not able to offer totally optimal bidding which conforms to optimization based on theoretical models and they usually do this using simple and rule of thumb methods and their bidding list is different given that they have prudential or non-prudential procedure in prices.

\section{Conclusion}

Restructuring based on supply function bid by firms to the market manager has been accepted in Iran's electricity market. But in spite of this fact, presenting and proposing the price-value list in this market is not based on models related to the process of restructuring and is practically on the basis of trial and error. Naturally this does not guarantee profit maximization for firms and decreases predictability of firms' behavior severely. Calculation of the effects of changes under these conditions especially calculating the effects of new reforms 
for continuation of restructuring or modification and liberalization of the price of energy inputs is not possible too.

The optimal model of biding under pay-as-bid conditions was presented in this survey besides reviewing the process and principles of restructuring. On the basis of it set of balanced optimal price-value for two power plants was calculated through required calculations about marginal cost, demand parameters, etc and was compared with the proposed price-value in the market. It indicated lack of conformity of set of the proposed price-value with that of optimal price-value especially in low amounts with regard to capacity.

Accordingly it is clear that application of models related to biding should be considered besides the process of restructuring in Iran's electric energy market. This issue specifically makes it possible to predict firms' behavior which is totally necessary for continuity and regulation of the restructuring process and other modifications in Iran's electric energy market such as price liberalization of energy inputs.

\section{References}

Anderson, E. J. and Philpott, A. B.(2002). Using supply functions for offering generation into an electricity market. Operation Research, Vol.50, pp.477-496.

Anderson, E. J. and Xu, H.(2002). Necessary and sufficient condition for optimal offers in electricity market. SIAM Journal on Control and Optimization, Vol.41, pp.1212-1228.

Dehesh, M.H. (2010). Supply function equilibrium in electricity market: Theory of games approach (Master's thesis, Department of Administrative Sciences and Economics, University of Isfahan, Isfahan

Federico,G. and Rahman, D. (2003).Bidding in an electricity pay-as-bid auction. Journal of Regulatory Economics, Vol.24, No. 2, pp.175-211.

Garcia, A. and Arbeláez, L.E. (2002).Market power analysis for the Colombian electricity market. Energy Economics, Vol. 24, pp.217-229.

Holmerg, P. (2008). Uniqe supply function equilibrium with capacity constraint. Energy Economics, Vol.30,pp.148-172.

Holmberg, P. (2009). Supply function equilibria of pay-as-bid auctions. Journal of Regulatory Economics, Vol.36, pp.154-177.

Klemperer, P. and Meyer, M. (1986). Price competition vs. quantity competition: the role of uncertainty. Rand Journal Economics, Vol.17, No.4, pp. 618-638.

Klemperer, P. and Meyer, M. (1989). Supply function equilibria in oligopoly under uncertainty. Econometrica, Vol. 57, No.6, pp.243-270.

Khoshakhlagh, R et al. (2012). Determining the basis of equations in the momentary electricity market. Case study of Isfahan electricity market. Journal of Economic Studies, Vol.46, pp. 65-87 Nazemi Ashni, A. (2012). Analysis of market power in Iran's electricity market, PhD thesis, Department of Administrative Sciences and Economics, University of Isfahan, Isfahan

Niu, H.(2005). Supply function equilibrium bidding strategies with fixed forward contracts. IEEE Transaction on Power System, Vol.20, No.4, pp.1859-1867.

Shweppe, F. (1988). Spot Pricing of Electricity. Boston, Kluwer Academic Publisher.

Sioshansi, R. andOren, Shmuel S. (2007). How good are supply function equilibrium models: an empirical analysis of the ERCOT balancing market. Journal of Regulatory Economics, Vol.31, pp.1-35. 
Stoft, s. (2003). Power System Economics. New York City: IEEE Press.

Tirole, J. and Fudenberg, D. (1995).Game Theory. Cambridge, Massachusetts:MIT Press. 